\title{
Dilute Russell's Viper Venom Time Measurement
}

National Cancer Institute

\section{Source}

National Cancer Institute. Dilute Russell's Viper Venom Time Measurement. NCI

Thesaurus. Code $C 96696$.

A measurement of the time it takes a plasma sample to clot after adding dilute Russell's viper venom. 